\title{
Internet of Services
}

\author{
DOI 10.1007/s12599-009-0066-Z
}

\section{The Authors}

\author{
Prof. Dr. Peter Buxmann \\ Technische Universität Darmstadt \\ Chair of Information Systems \\ Hochschulstraße 1 \\ 64289 Darmstadt \\ Germany \\ buxmann@is.tu-darmstadt.de
}

Prof. Dr. Thomas Hess

Ludwig-Maximilians-

Universität München

Institute for Information

Systems and New Media

Ludwigstr. 28

80539 München

Germany

thess@bwl.Imu.de

\section{Dr. Rainer Ruggaber}

SAP AG

SAP Research Center CEC Karlsruhe

Vincenz-Prießnitz-Str. 1

76131 Karlsruhe

Germany

rainer.ruggaber@sap.com

This article is also available in German in print and via http://www. wirtschaftsinformatik.de: Buxmann P, Hess T, Rugabber R (2009) Internet der Dienste. WIRTSCHAFTSINFORMATIK. doi: 10.1007/11576-009-0187-5.
The service sector is one of the strong growth markets world-wide. In $2008,70 \%$ of the macroeconomic value added in the Federal Republic of Germany was generated by the service industry. This constitutes an increase of around 50 billion euro compared to 2007. A study commissioned by the German Federal Ministry of Economics and Technology concludes that there is growth potential in particular with regard to IT services.

Taking this into account, the vision of the "Internet of Services" is to enable service vendors to offer their services via the internet. Depending on the possible degree of digitalization services can be offered and demanded world-wide. The Internet of Services consists of participants, an infrastructure for services, business models and the services themselves. Services are offered and combined into value-added services by various suppliers; they are communicated to users as well as consumers and are accessed by them via various channels.

Such services can support both functional and technical features. Apart from technical aspects, several business-related questions arise: What are sustainable business models for suppliers of such services? To what extent should interfaces or access to platforms be based upon open standards? Which positions can be taken by suppliers of traditional software or media in such markets? How can billing be organized in an efficient way? To what extent is regulation of service markets necessary from an economic point of view? Another interesting question arises with regard to who actually offers such services. Of course, "traditional" companies like SAP, Oracle, Microsoft or Google are among the suppliers. In addition, an increasing number of services are offered by suppliers that are not supported by one of the traditional companies. This, for example, could recently be observed in form of services for the iPhone or for platforms like Facebook.

There are a growing number of projects in business and information systems engineering dealing with the subject "Internet of Services". The most prominent one is the project THESEUS. It was initiated by the German Federal Ministry of Economics and Technology and deals with technical as well as economic aspects of the issue. In addition, there are several smaller initiatives in different locations which are concerned with particular aspects of the subject, e. g. security. The aim of this issue of Business and Information Systems Engineering is to provide an overview of these activities.

The contribution of Benjamin Blau, Clemens van Dinther, Tobias Conte, Yongchun $\mathrm{Xu}$, and Christof Weinhardt from Universität Karlsruhe (TH) and the Research Center for Information Technology (FZl) investigates the main components of Service Value Networks. For the coordination of such networks the authors develop a scalable, multidimensional auction mechanism which organizes the allocation and the price setting of complex services.

The article by Alexander Benlian, Thomas Hess, and Peter Buxmann from LMU Munich and Technical University Darmstadt addresses Software-as-a-Service (SaaS) as a relatively new paradigm of providing enterprise applications as a service. Within a quantitative empirical study they analyze different factors influencing the decision about SaaS-adoption.

Daniel Oberle, Nadeem Bhatti, Saartje Brockmans, Michael Niemann, and Christian Janiesch from SAP Research CEC Karlsruhe, Fraunhofer IGD Darmstadt, ontoprise GmbH Karlsruhe, Technical University Darmstadt and SAP Research CEC Brisbane address the organization of information in the Internet of Services. Their research is embedded in the THESEUS/TEXO project.

In the column "BISE - State-of-the-Art", Christof Weinhardt, Arun Anandasivam, Benjamin Blau, Nikolay Borissov, Thomas Meinl, Wibke Michalk, and Jochen Stößer from Universität Karlsruhe (TH) give an overview of Cloud Computing. 
The BISE - Catchword article by Nils-Holger Schmidt, Koray Erek, Lutz M. Kolbe, and Ruediger Zarnekow from Georg-August-University Göttingen and Technical University Berlin deals with sustainable information management.

We would like to express our thanks to the authors of this issue and also to all those whose contributions could not be accepted. Likewise, we would like to thank the reviewers who dealt with the submitted manuscripts in a differentiated way - sometimes even in several rounds. Furthermore, we would like to thank the editorial office of Business and Information Systems Engineering for the translation of the articles as well as Janina Ristl from Technical University Darmstadt for her outstanding support concerning the coordination of this issue. We hope you will find reading the papers interesting and inspiring.

Peter Buxmann

Thomas Hess

Rainer Ruggaber 